say that 'following emergence from the sea, organisms' further 'developed their own internal sea'. I was troubled over my breakfast on Boxing Day with images of evolutionary jumps that would alarm any rightthinking person!

My own knowledge of the evolution of homeostatic mechanisms as well as the origin of the species is really limited to my leisure reading of Gould, Dawkins et al.
There are also some vestiges of memories of undergraduate lectures on Fick's law of diffusion. Professor Allison's paper has further enlightened this soul as well as causing a smile over my toast and orange juice!

IAN R THOMPSON

Locum SpR, GUM/HIV

Chelsea and Westminster Hospital, London

\title{
Cannabis - the right decision but the wrong way to go about it?
}

I thought Charles would take a very strong line on drugs but nevertheless I was interested in his reaction to the somewhat more liberal approach that I sympathise with.

'Charles, what do you think about the downgrading of cannabis?' I asked. 'I think you are likely to take a harder line on this than I.'

'Yes probably,' he said, 'but just because I would take a very hard line on enforcement of the law it doesn't mean that I believe that change in the law is always inappropriate.'

'So you approve of the changes?'

'That's an over simplification Coe, but before we discuss the implications, I am sure there is one point with which you will agree: the legal status on cannabis has nothing to do with its possible use as a prescription drug for medical purposes.'

'Absolutely,' I said.

'It follows then, that it is dishonest to use the probable positive outcome of the investigations of the medical use of cannaboids as an argument in favour of changing its legal status.'

'Agreed,' I said 'and sometimes this is not drawn sufficiently forcibly to the attention of the protagonists who argue thus and should know better.'

'As to the original question I think there are three things to consider. Firstly, is cannabis potentially dangerous; secondly, is the potential hazard sufficiently different from drugs in the same group to justify a change; and thirdly, how should the change be made?'

'Surely you should also ask whether the cost of the change justifies the benefits of downgrading?'

'Are you concerned about the administrative cost, Coe?'

'Not really', I replied

'Do you mean that misconceived perceptions about the implication of the change of status such as "so it's harmless after all”, might increase its use?'

'That's right! It's often a major component of the argument of those who are opposed to change. I do have some sympathy with their fears.'

'I intended to cover that in my third point.' He continued: 'Let's take the first two points and agree that cannabis is potentially harmful, but on balance it is less hazardous than drugs in the same group.' 
'Are you accepting those points for the sake of argument Charles, or do you really believe that cannabis is relatively less hazardous?'

'It may surprise you Coe, but I think probably that argument is sustainable, so we are left with the third point. How should the change have been made in a way and at a time that did not lead to the feeling that it is either harmless or legal to use it?'

'How would you have managed that?'

'I would have allowed an interval between the decision and the change in the law long enough for the subject to become less topical. In the meanwhile I would educate the public that possible medical applications have nothing to do with "recreational" (how I dislike that word in this context) use.'

'But how long would you wait Charles? Surely it begs the question: "how long is a piece of string?"

'Yes, you're quite right, but the law does require revising from time to time. A decent interval is difficult to define, and in this case would have been difficult to achieve with the likelihood of recurrent publicity. Nevertheless, I would have tried to include the change in legislation that was clearly needed for other reasons, or engineered to appear so. In other words, I would only make the change at the time when it was explicitly stated to the public that this was a general review of drug categories and the status of each and every drug had been considered during the change of schedule.'

'And if cannabis were the only one?'

'That would have been unfortunate but I suspect there are other drugs which might be reviewed up or down. Even if cannabis turns out to be the only one that needed regrading, one could truthfully say that there had been a general review, thus making an emphatic statement that drugs of all categories are dangerous, ring much truer.'

'And so help with enforcement?'

'Yes, there is nothing in what I have said to suggest that I am softening in my views on enforcement, but you must get the right message over', he replied.

'And the authorities have failed in this, Charles?'

'Singularly!'

I wonder whether our readers agree this would have been a better approach. 